\title{
The Most Effective Amount of Forward Movement for Oral Appliances for Obstructive Sleep Apnea: A Systematic Review
}

\author{
Yuki Sakamoto ${ }^{1, *}$, Akifumi Furuhashi ${ }^{2,+}$, Eri Komori ${ }^{3,+}$, Hiroyuki Ishiyama ${ }^{4,+}$, \\ Daichi Hasebe ${ }^{5,+}$, Kazumichi Sato ${ }^{6,+}+(1)$ and Hidemichi Yuasa ${ }^{7, \dagger}$ \\ 1 Department of Oral Surgery, Hironokogen Hospital, 3-1-1 Kitayamadai Nishi-ku Kobe-shi, \\ Hyogo 6512215, Japan \\ 2 Department of Oral and Maxillofacial Surgery, Aichi Medical University, 1-1 Yazakokarimata Nagakute-shi, \\ Aichi 4801103, Japan \\ 3 Division of Medicine for Function and Morphology of Sensor Organ, Dentistry and Oral Surgery, Osaka \\ Medical College. 2-7 Daigaku-machi Takatsuki-shi, Osaka 5698686, Japan \\ 4 Orofacial Pain Management, Graduate School of Medical and Dental Sciences, Tokyo Medical and Dental \\ University (TMDU), 1-5-45 Yushima Bunkyo-ku, Tokyo 1138510, Japan \\ 5 Division of Reconstructive Surgery for Oral and Maxillofacial Region, Department of Tissue Regeneration \\ and Reconstruction, Niigata University Graduate School of Medical and Dental Sciences, 2-5274 \\ Gakkocho-Dori, Cyuo-ku, Nigata-shi, Nigata 9518514, Japan \\ 6 Department of Oral Medicine, Oral and Maxillofacial Surgery, Tokyo Dental College, 5-11-13 Sugano \\ Ichikawa-shi, Chiba 2728513, Japan \\ 7 Department of Oral and Maxillofacial Surgery, National Hospital Organization Toyohashi Medical Center, \\ 50 Imure-chou Aza Hamamichi-Ue, Toyohashi-shi, Aichi 4408510, Japan \\ * Correspondence: s.yukioutdoor@gmail.com; Tel.: +81-078-994-1155 \\ + These authors contributed equally to this work.
}

Received: 30 July 2019; Accepted: 30 August 2019; Published: 4 September 2019

\begin{abstract}
This systematic review clarifies the amount of effective protrusion in mandibular advancement devices of oral appliances required for obstructive sleep apnea (OSA). The systematic review adhered to the Preferred Reporting Items for Systematic Reviews and Meta-Analysis (PRISMA) guidelines. Review Manager 5 and GRADEpro were used to combine trials and analyze data. The present review included three studies. In mild to moderate OSA cases, measured using the apnea-hypopnea index (AHI), 50\% protrusion was more effective than $75 \%$ protrusion. However, $75 \%$ protrusion was more effective for severe cases. Sleep stage, Epworth Sleepiness Scale (ESS), snoring index, and side effects significantly differed between the groups. Additionally, $75 \%$ protrusion was more effective (AHI: 0.38, 95\% CI: -0.89 to $1.65, p=0.56$; sleep stage 3: -1.20 , 95\% CI: 9.54-7.14, $p=0.78$; ESS: $1.07,95 \%$ CI: -0.09 to $2.24, p=0.07$; snoring index: $0.09,95 \%$ CI: $0.05-0.13, p<0.05$; side effects: RR: $1.89,95 \%$ CI: $0.36-9.92, p=0.45)$. As per the AHI, $75 \%$ protrusion was effective in severe cases, whereas $50 \%$ protrusion was effective in moderate cases. Analysis of different surrogate outcomes indicated that $75 \%$ protrusion was more effective. Further, well-designed, larger trials should determine the benefits for patients. Additionally, investigations of adherence and side effects with long-term follow-up are needed.
\end{abstract}

Keywords: oral appliance; mandibular protrusion; obstructive sleep apnea; systematic review

\section{Introduction}

More than 3 million people have sleep disorders such as obstructive sleep apnea (OSA), which also includes latent sleep apnea. OSA has been shown to be associated with hypertension, depression, 
and lifestyle-related diseases [1-3]. OSA is commonly treated with continuous positive airway pressure (CPAP) or oral appliances (OAs). CPAP machines are usually prescribed to patients with an apnea-hypopnea index (AHI) between moderate and severe. OAs created by dentists are often prescribed for mild to moderate cases. In Japan, OA therapy is provided through the National Health Insurance and appliances such as monobloc and mandibular advancement devices (OAm) are often used to balance the costs. Many clinicians have set the mandibular protrusion as $50 \%-70 \%$ of the maximum. Initial observations in clinical settings indicate that OAs become inefficient owing to the advancement of the disease. Greater protrusion results in a larger airway that may be considered good; however, symptoms such as temporomandibular joint pain, a side effect of OAs, might appear and complicate the situation. Bartolucci et al. [4] reported no difference in the effectiveness of OAs with an incidence of forward protrusion of more than $50 \%$. Nonetheless, their conclusion was drawn based on the results of an examination of the success rate of protrusion amounts in randomized control trials. As for the monobloc-type devices, adjustments are required depending on the comfort of the patient and effects on their OSA, but this adjustment is complicated and troublesome. Such adjustment is necessary to indicate the initial bite setting for clinicians. This systematic review examined the most effective protrusion of mandibular orientation of OAs afresh.

\section{Materials and Methods}

This systematic review was performed following the Preferred Reporting Items for Systematic Reviews and Meta-Analyses (PRISMA) guidelines. The protocol for this review was registered with the international prospective register of systematic reviews (PROSPERO) with the registration number CRD42019136242.

\subsection{Inclusion and Exclusion Criteria}

\subsubsection{Inclusion Criteria}

1. The definition of $\mathrm{OA}$

- Equipment that acquires upper and lower jaw impressions for every patient, which is thus precisely produced.

- A device that exerts an effect by maintaining the lower jaw in the forward direction.

2. The diagnostic and therapeutic effects of OSA are determined by either polysomnography (PSG) or out-of-center sleep testing (OCST).

\subsubsection{Exclusion Criteria}

1. Subject is under 18 years of age.

2. The device is ready-made.

3. The device exerts an effect by maintaining the tongue in the forward orientation.

\subsubsection{Conditions Not Included in the Definition}

1. Equipment size, design

2. Material characteristics (e.g., hard, soft, and hybrid)

3. Thickness

4. Detailed design of the device (e.g., type of connector in separate type and presence of integral air hole)

5. Excluding comparison with forward movement of $0 \mathrm{~mm}$ (placebo) 


\subsection{Literature Search}

The primary database used was MEDLINE (via PubMed), the Cochrane Central Register of Controlled Trials (CENTRAL), and Japan Medical Abstracts Society Research (Ichushi-Web). No limits were set with respect to the year of study or language. We selected only randomized controlled trials (RCTs) in the OAm design. A thorough literature search was conducted that was completed on 27 April 2019. A search strategy was executed using the keywords shown in Box 1.

Box 1. Keywords used for the literature search.

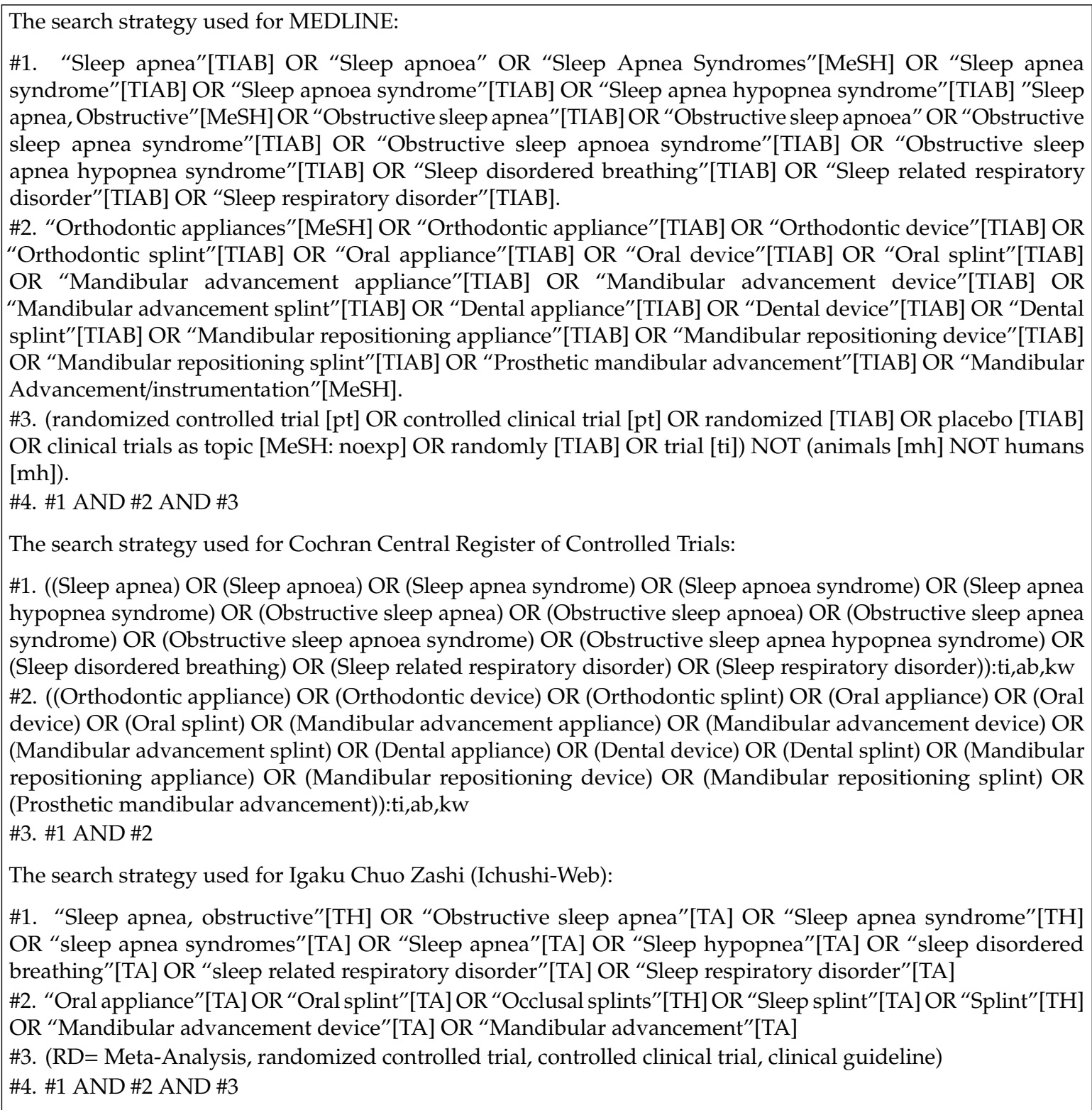




\subsection{Study Selection Procedure}

The selection of papers was made in two stages. First, two authors individually selected the articles from titles and abstracts. If in doubt, another author checked for confirmation. In the second stage, full-text papers were reviewed by two authors, and if in doubt, three authors examined them.

\subsection{Data Extraction}

Data were extracted independently by three authors. The following important information was collected: author name, year of publication, duration of the study arms, age of participants, study design, number of patients and dropouts, mean age, severity of AHI, and mean body mass index (BMI). The primary outcomes were mortality rates and cardiovascular events. Surrogate outcome \#1 consisted of treatment effect, including AHI (respiratory disturbance index: RDI, respiratory event index: REI), lowest $\mathrm{SpO}_{2}$, arousal index, sleep efficiency, sleep stage (NREM stage 3), subjective daytime sleepiness (the Epworth Sleepiness Scale: ESS), and snoring index (SI). Surrogate outcomes \#2-4 were adherence (the duration of OA usage at night and the number of days the device was used in the preceding week), sleep-related quality of life (SF-36 physical component and SF-36 mental component), and hypertension (systolic blood pressure and diastolic blood pressure), respectively. Surrogate outcome \#5 consisted of side effects, including temporomandibular disorders (arthralgia or myalgia), tooth pain, occlusal changes (overbite or overjet), changes in occlusal contact, and changes in bite force. Finally, surrogate outcome \#6 was patient preference. If the standard error of the mean (SEM) was reported for outcomes in the examined studies, the standard deviation (SD) was then calculated from the number of subjects in the study and the reported SEM.

\subsection{Quality Assessment of Included Studies}

The Grading of Recommendations, Assessment, Development, and Evaluation (GRADE) Approach was used to evaluate the overall quality of the evidence utilizing Review Manager 5 (Nordic Cochrane Centre, Cochrane Collaboration, 2014 Copenhagen, Denmark). Quality assessment of the study and any discrepancies were resolved by discussion among the seven authors.

\section{Results}

\subsection{Identification and Description of Included Studies}

The search identified 617 articles from the database (201 from MEDLINE, 385 from CENTRAL, and 31 from Japan Medical Abstracts Society Research) (Figure 1). After removing 158 duplicates, we conducted a title and abstract search of each study and excluded 441 articles. Twenty-two studies were retrieved for full-text assessment. Nineteen articles were excluded, as in those, comparisons were made with placebo $(n=5)$, OA protrusion study was absent $(n=5)$, protrusion amount was not disclosed $(n=3)$, titrating amount was not set up $(n=2)$, the study was under clinical trial $(n=1)$, no full text was available $(\mathrm{n}=1)$, contradicting outcomes were observed $(\mathrm{n}=1)$, and the subjects of the study were children $(n=1)$. The remaining three publications were included for detailed analysis. Table 1 presents the characteristic of the included studies [5-7]. 


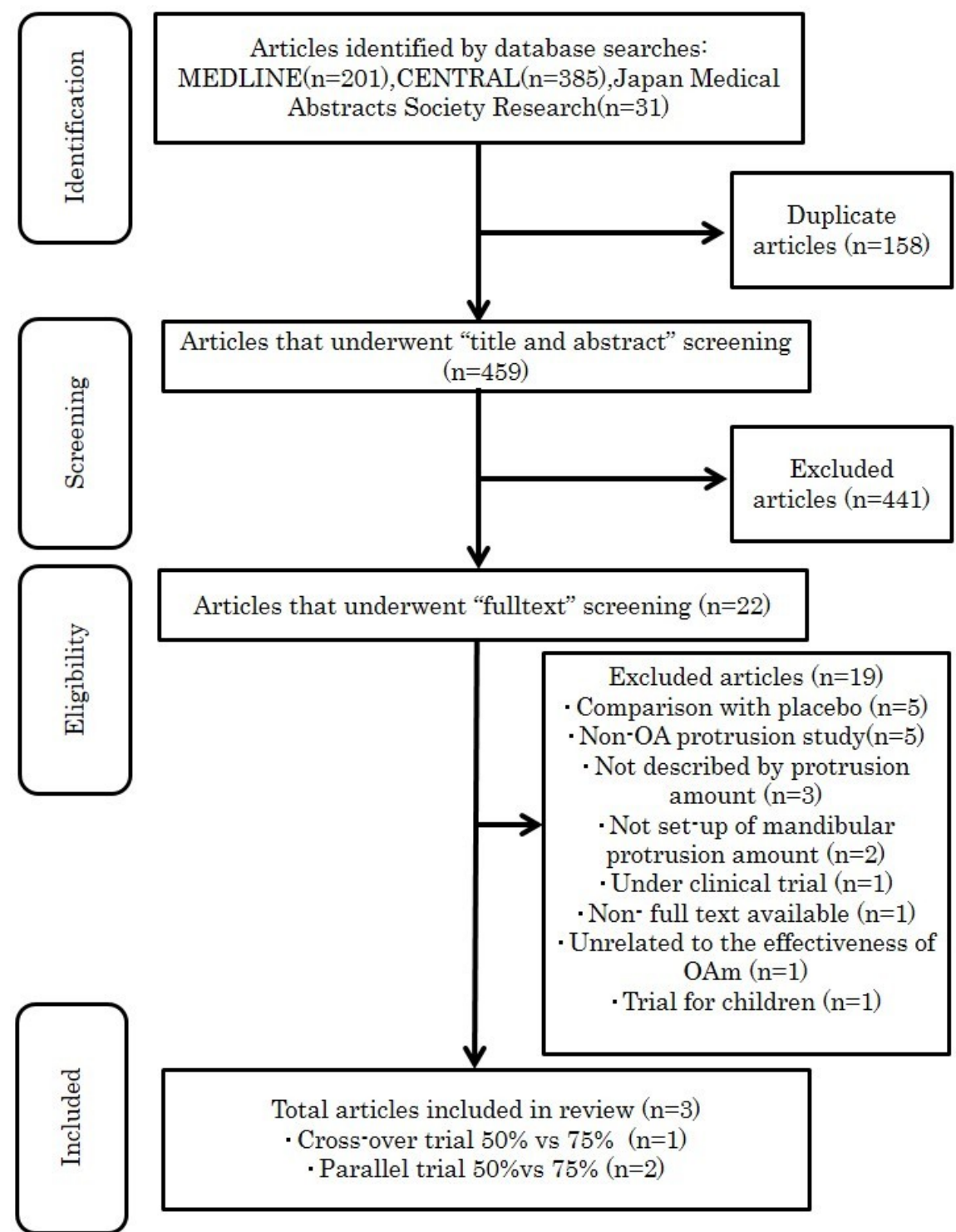

Figure 1. Flow diagram of the literature search.

The Aarab (2009) [5] study was a crossover trial, wherein the subject observation period was 1.5 months for the use of OAs against mild OSA. It compared 50\% and 75\% mandibular protrusion positions. Tegelberg (2003) [6] was a parallel trial for mild to moderate OSA over a 12-month observation period comparing $50 \%$ and $75 \%$ protrusion. Walker-Engstrom (2003) [7] was yet another parallel test in which subjects with severe OSA were observed for 6 months.

\subsection{Meta-Analysis}

The primary outcome of OSA treatment is the improvement of life prognosis and the prevention of cardiovascular disease. However, surrogate outcomes are often used as read outs because they require long-term research. A list of surrogate outcomes based on available reports was charted out $[8,9]$. As a result, there were reports on the effects of AHI, sleep stage, ESS, SI, and side effects (Figure 2). We performed subgroup analysis organized by severity of the three studies. The severity of OSA was classified by AHI (mild: $5 \leq \mathrm{AHI}<15$, moderate: $15 \leq \mathrm{AHI}<30$, severe: $30 \leq \mathrm{AHI}$ ). 
Table 1. Characteristics of the included studies.

\begin{tabular}{|c|c|c|c|c|c|c|c|c|c|}
\hline Study/Year & Study Design & OSA Severity & Duration & Control Type & $\begin{array}{l}\text { Number of the } \\
\text { Beginning } \\
\text { Patients }\end{array}$ & $\begin{array}{c}\text { Number of } \\
\text { the Patients } \\
\text { Completed } \\
\text { Trial }\end{array}$ & $\begin{array}{c}\text { Age } \\
\text { (Mean SD) }\end{array}$ & $\begin{array}{c}\text { BMI } \\
\text { (Mean SD) }\end{array}$ & Outcome \\
\hline \multirow{2}{*}{ 1, Aarab 2009} & \multirow{2}{*}{$\begin{array}{l}\text { 2-armed } \\
\text { crossover; } \\
\text { randomised }\end{array}$} & \multirow{2}{*}{ mild OSA } & \multirow{2}{*}{1.5 months } & \multirow{2}{*}{$\begin{array}{c}50 \%, 75 \% \\
\text { protrusion }\end{array}$} & $50 \%: 20$ & $50 \%: 17$ & $\begin{array}{c}50 \%: 51.8 \\
(49.0-54.6)\end{array}$ & $50 \%: 27.6 \pm 3.3$ & \multirow{2}{*}{$\begin{array}{c}\text { AHI, ODI, Lowest } \mathrm{SPO}_{2} \\
\text { Total sleep time, Stage3, } \\
\text { Stage REM, ESS }\end{array}$} \\
\hline & & & & & $75 \%: 20$ & $75 \%: 17$ & $\begin{array}{c}75 \%: 54.4 \\
(52.4-56.4)\end{array}$ & $75 \%: 27.6 \pm 3.0$ & \\
\hline \multirow{2}{*}{ 2, Tegelberg 2003} & \multirow{2}{*}{$\begin{array}{l}\text { 2-armed } \\
\text { Parallel; } \\
\text { randomised }\end{array}$} & \multirow{2}{*}{$\begin{array}{l}\text { mild to } \\
\text { moderate } \\
\text { OSA }\end{array}$} & \multirow{2}{*}{12 months } & \multirow{2}{*}{$\begin{array}{l}50 \%, 75 \% \\
\text { protrusion }\end{array}$} & $50 \%: 38$ & $50 \%: 29$ & $\begin{array}{c}50 \%: 51.8 \\
(49.0-54.6) \\
\end{array}$ & $\begin{array}{c}50 \%: 27.4 \\
(26.4-28.4) \\
\end{array}$ & \multirow{2}{*}{ AHI, AI, ODI } \\
\hline & & & & & $75 \%: 36$ & $75 \%: 26$ & $\begin{array}{c}75 \%: 54.4 \\
(52.4-56.4)\end{array}$ & $\begin{array}{c}75 \%: 27.9 \\
(26.6-29.3)\end{array}$ & \\
\hline \multirow{2}{*}{$\begin{array}{l}\text { 3, Walker-Engstrom } \\
2003\end{array}$} & \multirow{2}{*}{$\begin{array}{l}\text { 2-armed } \\
\text { Parallel; } \\
\text { randomised }\end{array}$} & \multirow{2}{*}{ severe OSA } & \multirow{2}{*}{6 months } & \multirow{2}{*}{$\begin{array}{l}50 \%, 75 \% \\
\text { protrusion }\end{array}$} & $50 \%: 42$ & $50 \%: 37$ & $\begin{array}{c}50 \%: 54.3 \\
(52.2-56.4) \\
\end{array}$ & $50 \%: 30.5 \pm 1.4$ & \multirow{2}{*}{ AHI, AI, ODI, SI, ESS } \\
\hline & & & & & $75 \%: 42$ & $75 \%: 40$ & $\begin{array}{c}75 \%: 50.4 \\
(47.7-53.1)\end{array}$ & $75 \%: 30.2 \pm 1.2$ & \\
\hline
\end{tabular}




\subsubsection{Treatment Effect}

Using AHI as the standard measurement, $75 \%$ protrusion is effective $(0.38,95 \% \mathrm{CI}$ : -0.89 to 1.65 ; $p=0.58$ ), and if classified according to severity, $75 \%$ protrusion is effective in moderate-severe OSA (1.7, 95\% CI: -2.33 to $5.73 ; p=0.41)$. At mild to moderate levels, $50 \%$ protrusion was effective $(-0.3$, $95 \%$ CI: -1.85 to $1.25 ; p=0.70)$. ESS has been reviewed in two papers, and overall, $75 \%$ protrusion was more effective $(1.07,95 \%$ CI: -0.09 to $2.24 ; p=0.07)$. REM sleep in stage 3 was found to be more often associated with $75 \%$ protrusion $(-1.20,95 \%$ CI: -9.54 to $7.14 ; p=0.78)$, and SI improved with $75 \%$ protrusion $(0.09,95 \%$ CI: $0.05-0.13 ; p<0.05)$. The horizontal axis of the forest plot in Figure 2 is ( $75 \%$, and $50 \%$ protrusion better); only sleep stage 3 is reversed.

\subsubsection{Side Effects}

Side effects were reviewed in two papers, and $75 \%$ protrusion had fewer side effects than in $50 \%$ protrusion (RR: 1.89 ; 95\% CI: 0.36-9.92; $p=0.45$ ).

\subsection{GRADE Evidence Profile}

The evidence profile was calculated using the GRADEpro software, as shown in Table 2 . The quality of evidence was low due to the risk of bias and imprecision. Because the number of eligible articles was $<10$, a funnel plot was not used to assess publication bias in this meta-analysis.

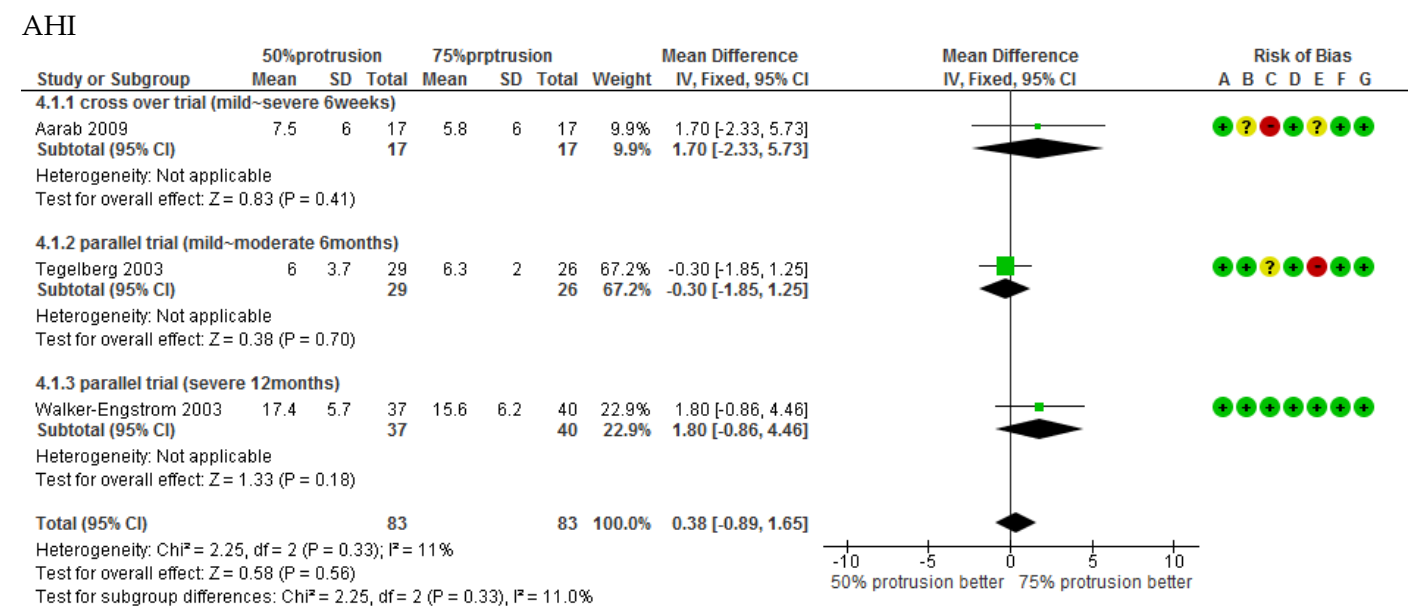

Sleep Stage 3

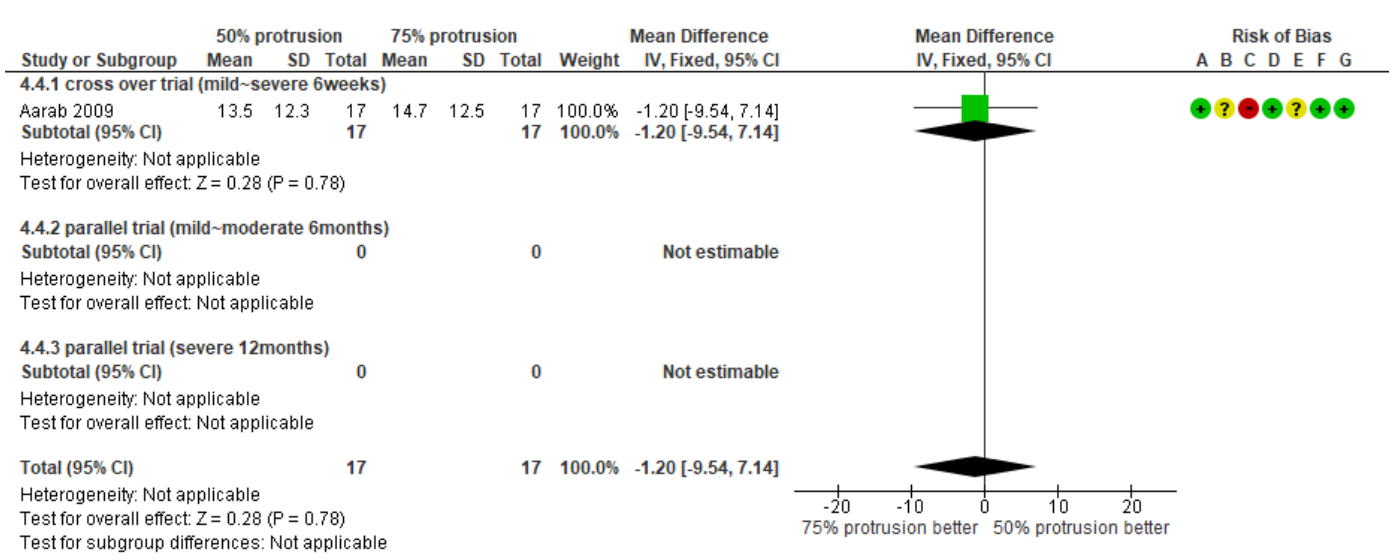

Figure 2. Cont. 
ESS

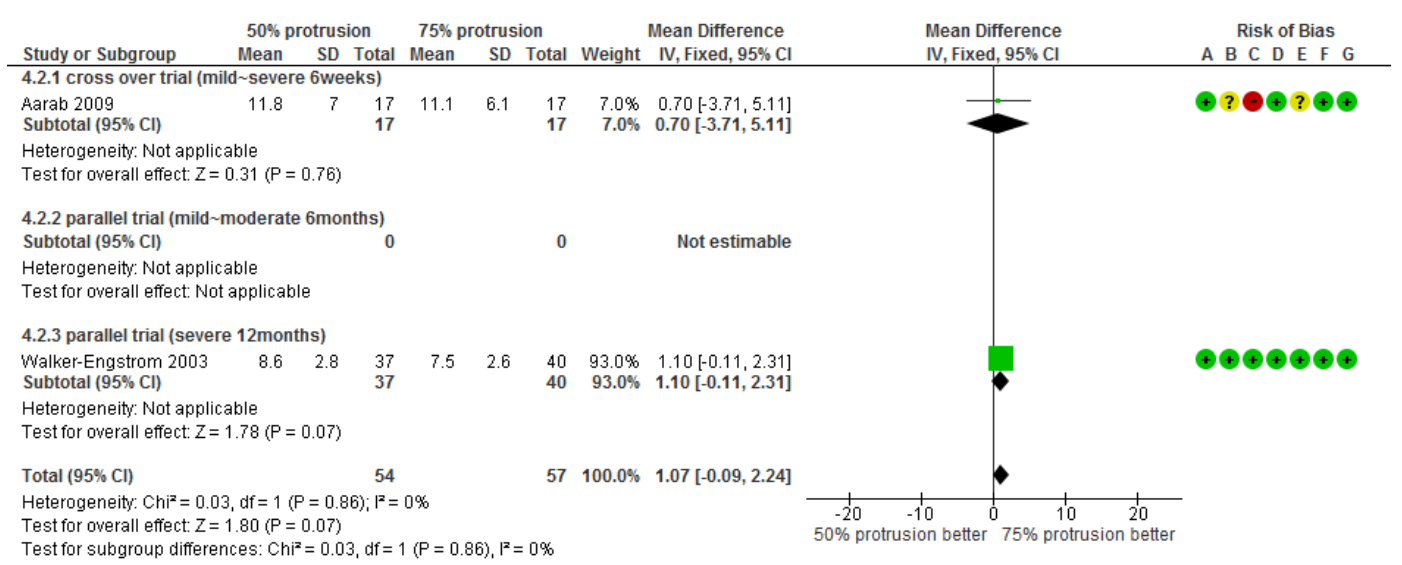

Snoring Index

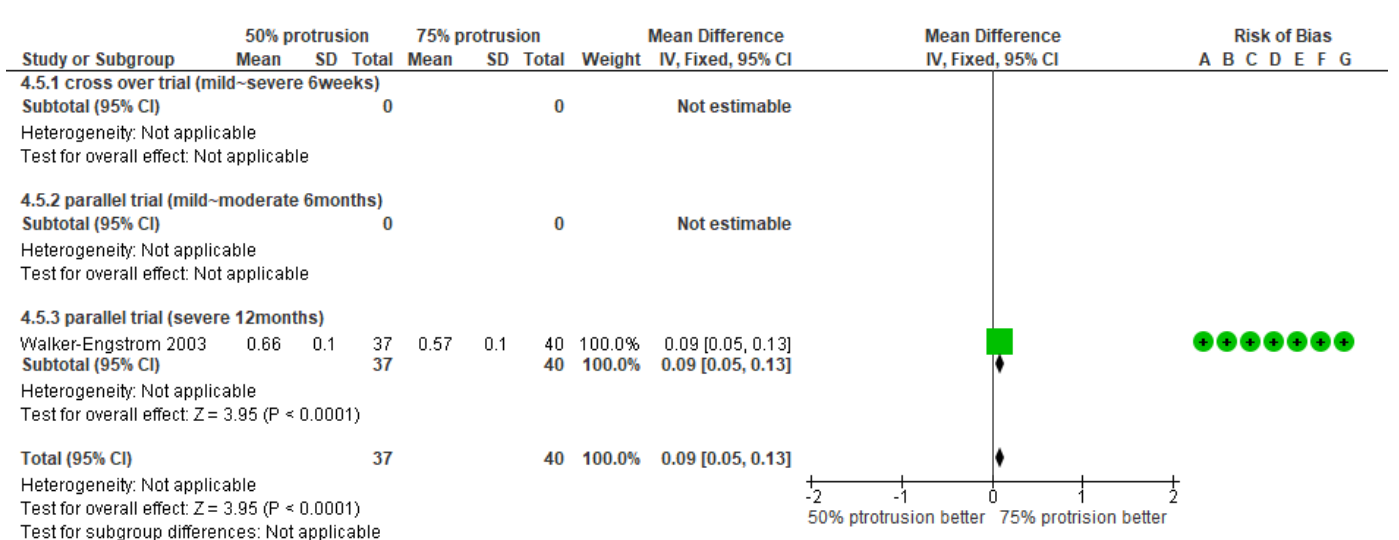

Side Effects

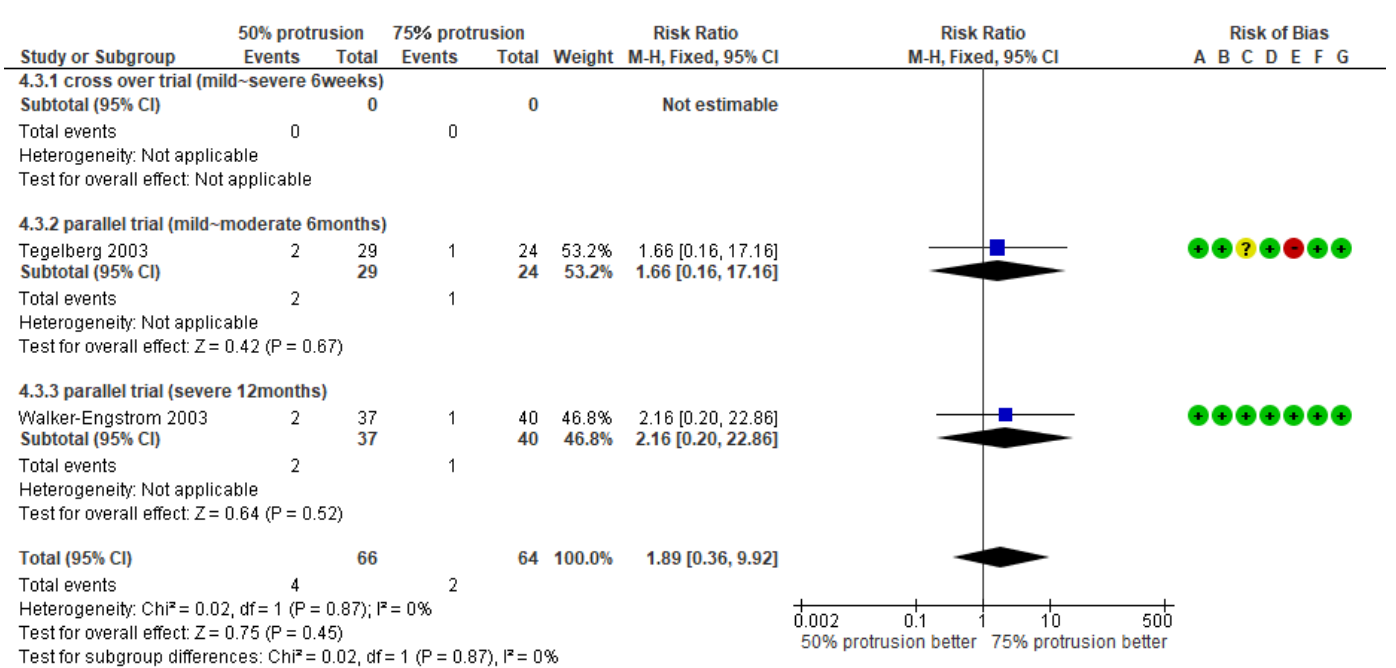

Figure 2. Forest plots showing the mean surrogate outcome differences between $50 \%$ protrusion and $75 \%$ protrusion in the included studies. The horizontal axis of the forest plot in Sleep Stage 3 is reversed (75\%, and 50\% protrusion better). Risk of bias legend: (A) Random sequence generation (selection bias), (B) Allocation concealment (selection bias), (C) Blinding of participants and personnel (performance bias), (D) Blinding of outcome assessment (detection bias), (E) Incomplete outcome data (attrition bias), (F) Selective reporting (reporting bias), and (G) Other bias. 
Table 2. Assessment of quality using the Grading of Recommendations, Assessment, Development, and Evaluation (GRADE) system for comparison of the studies.

\begin{tabular}{|c|c|c|c|c|c|c|c|c|c|c|c|}
\hline \multicolumn{7}{|c|}{ Certainty Assessment } & \multicolumn{2}{|c|}{ No. of Patients } & \multicolumn{2}{|r|}{ Effect } & \multirow{3}{*}{ Certainty } \\
\hline \multirow{2}{*}{$\begin{array}{l}\text { No. of } \\
\text { studies }\end{array}$} & \multirow{2}{*}{$\begin{array}{l}\text { Study } \\
\text { Design }\end{array}$} & \multirow{2}{*}{$\begin{array}{l}\text { Risk of } \\
\text { Bias }\end{array}$} & \multirow{2}{*}{ Inconsistency } & \multirow{2}{*}{ Indirectness } & \multirow{2}{*}{ Imprecision } & \multirow{2}{*}{$\begin{array}{c}\text { Other } \\
\text { Considerations }\end{array}$} & \multirow{2}{*}{$\begin{array}{c}50 \% \\
\text { Protrusion }\end{array}$} & \multirow{2}{*}{$\begin{array}{c}75 \% \\
\text { Protrusion }\end{array}$} & \multirow{2}{*}{$\begin{array}{l}\text { Relative } \\
(95 \% \text { CI })\end{array}$} & \multirow{2}{*}{$\begin{array}{c}\text { Absolute } \\
(95 \% \mathrm{CI})\end{array}$} & \\
\hline & & & & & & & & & & & \\
\hline \multicolumn{12}{|c|}{ AHI } \\
\hline \multirow{2}{*}{3} & \multirow{2}{*}{$\begin{array}{l}\text { randomised } \\
\text { trials }\end{array}$} & \multirow{2}{*}{ serious $^{a}$} & \multirow{2}{*}{ not serious } & \multirow{2}{*}{ not serious } & \multirow{2}{*}{ very serious ${ }^{b}$} & \multirow{2}{*}{ none } & \multirow{2}{*}{83} & \multirow{2}{*}{83} & \multirow[t]{2}{*}{-} & MD 0.38 higher & \multirow[t]{2}{*}{ VERY LOW } \\
\hline & & & & & & & & & & (0.89 lower to 1.65 higher) & \\
\hline \multicolumn{12}{|c|}{ AHI - Cross over trial mild severe 6 weeks } \\
\hline 1 & $\begin{array}{l}\text { randomised } \\
\text { trials }\end{array}$ & serious $\mathrm{b}$ & not serious & not serious & very serious ${ }^{b}$ & none & 17 & 17 & - & MD 1.7 higher & VERY LOW \\
\hline & & & & & AHI - parall & 1 trial mild $\sim \bmod$ & ate 6 months & & & & \\
\hline 1 & randomised & serious ${ }^{a, c}$ & not serious & not serious & very serious ${ }^{b}$ & none & 29 & 26 & - & MD 0.3 lower & VERY LOW \\
\hline 1 & trials & serious & not sentous & not sertous & very serrous & मापात & 29 & 20 & & (1.85 lower to 1.25 higher) & VEKY LUV \\
\hline & & & & & AHI - pa & allel trial severe & months & & & & \\
\hline 1 & randomised & not serious & not serious & not serious & very serious ${ }^{b}$ & none & 37 & 40 & - & MD 1.8 higher & LOW \\
\hline & & & & & & & & & & ( 0.86 lower to 4.46 higher) & \\
\hline & & & & & & ESS & & & & & \\
\hline 2 & trials & not sentous & not serious & not serious & very senous & Hणाए & 34 & Ji & & (0.09 lower to 2.24 higher) & LUN \\
\hline & & & & & & side effect & & & & & \\
\hline 2 & randomised & serious ${ }^{a}$ & not serious & not serious & very serious ${ }^{b}$ & none & $4 / 66(6.1 \%)$ & $2 / 64(3.1 \%)$ & RR 1.89 & 28 more per 1000 & VERY LOW \\
\hline & & & & & & & & & (0.36 to 9.92$)$ & $\begin{array}{c}\text { (from } 20 \text { fewer to } 279 \\
\text { more) }\end{array}$ & \\
\hline & & & & & & Stage 3,4 & & & & & \\
\hline 1 & randomised & serious $\mathrm{b}$ & not serious & not serious & very serious ${ }^{b}$ & none & 17 & 17 & - & MD 1.2 lower & VERY LOW \\
\hline & trials & & & & & & & & & (9.54 lower to 7.14 higher) & \\
\hline & & & & & & Snoring Index & & & & & \\
\hline 1 & randomised & not serious & not serious & not serious & very serious ${ }^{b}$ & none & 37 & 40 & - & MD 0.09 higher & LOW \\
\hline & trials & & & & & & & & & ( 0.05 higher to 0.13 higher) & \\
\hline
\end{tabular}

a: the rate of dropout exceeds $20 \%$ in Tegelberg's paper; b: the number of patients was very small. 


\section{Discussion}

There are two types of OAm: the monobloc type device and the bibloc-apnea splint type. In Japan, the monobloc type is widely used and the upper and lower parts of the device are fixed with resin. Therefore, the initial position of the device is important. Many dentists set mandibular protrusion at $70 \%$ at the beginning of treatment; however, whether this position is the best is unclear. This review revealed that $75 \%$ protrusion was effective for severe OSA and $50 \%$ protrusion was effective for moderate OSA. It is thought that $50 \%$ protrusion in severe cases does not ensure a sufficiently open airway. Improvements in sleep stage 3, ESS, and SI were observed with $75 \%$ protrusion compared with $50 \%$ protrusion. OAm have better effects when a larger forward protrusion is used. An increased protrusion ensures that a wide airway is opened, thereby ameliorating drowsiness. OAm causes the lower jaw enclosure to widen, and thus, the size of the airway is increased [10]. A larger mandibular protrusion results in a larger airway opening [11]. To answer the question of why people with high OSA severity have larger forward mandibular movement, the following observations were drawn. People with high OSA severity had a BMI average value above 30 (BMI: mild OSA, 50\% protrusion $=27.6 \pm 3.3$, mild OSA, $75 \%$ protrusion $=27.6 \pm 3.0$; mild to moderate OSA, $50 \%$ protrusion $=27.4$ (26.4-28.4), mild to moderate OSA, $75 \%$ protrusion $=27.9(26.6-29.3)$; severe OSA, $50 \%$ protrusion $=30.5 \pm 1.4$, severe OSA, $75 \%$ protrusion $=30.2 \pm 1.2$ ). We observed that obese patients had tongue hypertrophy, subsidence of the tongue base, and pharynx constriction [12]. Therefore, the airway can be expanded if it is further advanced. For patients with high OSA severity and high BMI, it is better for improvement of AHI to advance the mandibular more than $70 \%$.

However, side effects such as temporomandibular disorder and discomfort may be increased. Adverse effects of OAm, such as long-term use, tooth movement, short-term temporomandibular joint, and muscle pain, have also been reported, but only a few studies seem to compare the amount of forward movement [13]. Less than $75 \%$ protrusion of the mandible is a side effect; however, as this is observed in a very small number of cases, the validity of this side effect is difficult to determine. In a clinical setting, it is common to have pain when protrusion extends to the front of the temporomandibular joint. In the present study, the comparison between the two papers was also relatively small, and the side effects due to transfer as well as the limited number of side effects should be considered in the future. Further, in some patients, even $50 \%$ protrusion in mild cases may not be sufficient; hence, it is also necessary to combine other methods to decide the most effective mandibular protrusions. Examinations such as the snoring sound test, airway evaluation using an endoscope, and cephalogram analysis can assess the presence or absence of airway dilation according to forward orientation and detect abnormalities of skeletal and soft tissues [14,15]. However, it needs to be understood that an improvement in AHI does not guarantee good OAs. A long-term study of mandibular advancement devices should examine the various potential side effects. This systematic review has some limitations. The findings are limited by the number of studies included, the relatively small number of patients studied, the period of the study and methodological weaknesses (such as blinding of participants), BMI differences, and incomplete data acquisition. Moreover, the trials were mixed parallel and crossover. It is necessary to correct the design of the trials, increase the number of patients, and have a long-term view of the possible side effects.

\section{Conclusions}

Through this review, we recommend that for patients with severe OSA, it is beneficial to begin with a mandibular protrusion of approximately $70 \%$, and in cases of mild to moderate OSA, begin with that of approximately 50\%. Further, well-designed, larger trials are required to determine the long-term benefit for patients. Specifically, investigation of adherence and side effects of long-term follow-up are needed.

Author Contributions: Y.S. and A.F. contributed to the study design, data collection, interpretation, statistical analysis, and manuscript preparation. H.I. contributed to the data collection, interpretation, statistical analysis, 
and manuscript preparation. K.S. and H.Y. contributed to the data collection, interpretation, and statistical analysis. D.H. and E.K. contributed to the data collection.

Funding: This work was supported by grants from The Japanese Academy of Dental Sleep Medicine.

Acknowledgments: We would like to thank Haruko Kobayashi, Library, Aichi Medical University for supporting the literature search for this systematic review. This work was supported by the Japanese Academy of Dental Sleep Medicine.

Conflicts of Interest: The authors declare no conflict of interest.

\section{References}

1. Shamsuzzaman, A.S.; Gersh, B.J.; Somers, V.K. Obstructive Sleep Apnea: Implications for Cardiac and Vascular Disease. JAMA 2003, 290, 1906-1914. [CrossRef] [PubMed]

2. Expert Panel on Detection, Evaluation, and Treatment of High Blood Cholesterol in Adults (Adult Treatment panel III). Executive Summary of the Third Report of the National Cholesterol Education Program (NCEP). JAMA 2001, 285, 2486-2497. [CrossRef] [PubMed]

3. Mesarwi, O.A.; Sharma, E.V.; Jun, J.C.; Polotsky, V.Y. Metabolic Dysfunction in Obstructive Sleep Apnea: A Critical Examination of Underlying Mechanisms. Sleep Biol. Rhythms 2015, 13, 2-17. [CrossRef] [PubMed]

4. Bartolucci, M.L.; Bortolotti, F.; Raffaelli, E.; D'Antò, V.; Michelotti, A.; Alessandri Bonetti, G. The Effectiveness of Different Mandibular Advancement Amounts in OSA Patients: a Systematic Review and Meta-Regression Analysis. Sleep Breath. 2016, 20, 911-919. [CrossRef] [PubMed]

5. Aarab, G.; Lobbezoo, F.; Hamburger, H.L.; Naeije, M. Effects of an Oral Appliance with Different Mandibular Protrusion Positions at a Constant Vertical Dimension on Obstructive Sleep Apnea. Clin. Oral Investig. 2010, 14, 339-345. [CrossRef] [PubMed]

6. Tegelberg, A.; Walker-Engström, M.L.; Vestling, O.; Wilhelmsson, B. Two Different Degrees of Mandibular Advancement with a Dental Appliance in Treatment of Patients with Mild to Moderate Obstructive Sleep Apnea. Acta Odontol. Scand. 2003, 61, 356-362. [CrossRef]

7. Walker-Engström, M.L.; Ringqvist, I.; Vestling, O.; Wilhelmsson, B.; Tegelberg, A. A Prospective Randomized Study Comparing Two Different Degrees of Mandibular Advancement with a Dental Appliance in Treatment of Severe Obstructive Sleep Apnea. Sleep Breath. 2003, 7, 119-130. [CrossRef] [PubMed]

8. Aydin Guclu, O.; Ursavas, A.; Kasapoglu, F.; Ozarda, Y.; Bozyigit, C.; Ocakoglu, G.; Karadag, M. Relationship with Excessive Daytime Sleepiness and Serum Substance P Levels in OSAS Patients and the Effect of PAP Treatment. Sleep Biol. Rhythms 2019, 17, 355-361. [CrossRef]

9. Lakadamyali, H.; Kivanc, T.; Yilmaz Avci, A.Y. Correlation of Changes in the Red Blood Cell Distribution Width with the Response to Continuous Positive Airway Pressure in Patients with Obstructive Sleep Apnea. Sleep Biol. Rhythms 2019, 17, 141-148. [CrossRef]

10. Isono, S. Contribution of Obesity and Craniofacial Abnormalities to Pharyngeal Collapsibility in Patients with Obstructive Sleep Apnea. Sleep Biol. Rhythms 2004, 2, 17-21. [CrossRef]

11. Piskin, B.; Karakoc, O.; Genc, H.; Akay, S.; Sipahi, C.; Erdem, M.; Karaman, B.; Gorgulu, S.; Yetkin, S.; Ayyildiz, S. Effects of Varying Mandibular Protrusion and Degrees of Vertical Opening on Upper Airway Dimensions in Apneic Dentate Subjects. J. Orofac. Orthop. 2015, 76, 51-65. [CrossRef] [PubMed]

12. Joosten, S.A.; Hamilton, G.S.; Naughton, M.T. Impact of Weight Loss Management in OSA. Chest 2017, 152, 194-203. [CrossRef] [PubMed]

13. Hamoda, M.M.; Kohzuka, Y.; Almeida, F.R. Oral Appliances for the Management of OSA: an Updated Review of Literature. Chest 2018, 153, 544-553. [CrossRef] [PubMed]

14. Chan, A.S.; Lee, R.W.; Srinivasan, V.K.; Darendeliler, M.A.; Grunstein, R.R.; Cistulli, P.A. Nasopharyngoscopic Evaluation of Oral Appliance Therapy for Obstructive Sleep Apnoea. Eur. Respir. J. 2010, 35, 836-842. [CrossRef] [PubMed]

15. Ng, A.T.; Qian, J.; Cistulli, P.A. Oropharyngeal Collapse Predicts Treatment Response with Oral Appliance Therapy in Obstructive Sleep Apnea. Sleep 2006, 29, 666-671. [PubMed]

(C) 2019 by the authors. Licensee MDPI, Basel, Switzerland. This article is an open access article distributed under the terms and conditions of the Creative Commons Attribution (CC BY) license (http://creativecommons.org/licenses/by/4.0/). 